Article

\title{
Sintering Behavior and Microstructure of TiC-Me Composite Powder Prepared by SHS
}

\author{
Elena N. Korosteleva ${ }^{1,2, *}$, Victoria V. Korzhova ${ }^{2}$ and Maksim G. Krinitcyn ${ }^{1,2}$ \\ 1 Department of High Technology Physics in Mechanical Engineering, Tomsk Polytechnic University, \\ 30 Lenin av., 634050 Tomsk, Russia; krinmax@gmail.com \\ 2 Institute of Strength Physics and Materials Science of Siberian Branch of the Russian Academy of Sciences, \\ 2/4, pr. Akademicheskii, 634055 Tomsk, Russia; vicvic5@mail.ru \\ * Correspondence: elenak@ispms.tsc.ru; Tel.: +7-903-913-8002
}

Received: 29 June 2017; Accepted: 27 July 2017; Published: 31 July 2017

\begin{abstract}
Titanium, its alloys, and refractory compounds are often used in the compositions of surfacing materials. In particular, under the conditions of electron-beam surfacing the use of synthesized composite powder based on titanium carbide with a metal binder (TiC-Me) has a positive effect. These powders have been prepared via the self-propagating high-temperature synthesis (SHS) present in a thermally-inert metal binder. The initial carbide particle distribution changes slightly in the surfacing layer in the high-energy rapid process of electron-beam surfacing. However, these methods also have their limitations. The development of technologies and equipment using low-energy sources is assumed. In this case, the question of the structure formation of composite materials based on titanium carbide remains open, if a low-energy and prolonged impact in additive manufacturing will be used. This work reports the investigation of the sintered powders that were previously synthesized by the layerwise combustion mode of a mixture of titanium, carbon black, and metal binders of various types. The problems of structure formation during vacuum sintering of multi-component powder materials obtained as a result of SHS are considered. The microstructure and dependences of the sintered composites densification on the sintering temperature and the composition of the SH-synthesized powder used are presented. It has been shown that under the conditions of the nonstoichiometric synthesized titanium carbide during subsequently vacuum sintering an additional alloy formation occurs that can lead to a consolidation (shrinkage) or volumetric growth of sintered TiC-Me composite depending on the type of metal matrix used.
\end{abstract}

Keywords: titanium carbide; self-propagating high-temperature synthesis (SHS); metal binder; composite powders; sintering

\section{Introduction}

Titanium-based materials possess many unique properties that enable them to be used in a wide range of applications in various industries [1-6]. Titanium-containing materials are in demand both as casting alloys and as powder composites. Interest in the powder composite materials, in particular, has grown considerably with the development of additive manufacturing, including surfacing processes and 3D-printing of finished parts and products. The desire to create volumetric printing products with complex surface geometry gave an additional incentive for the study of powder materials containing titanium [4-6]. Composites based on titanium carbide occupy a special place among the known groups of titanium materials. The high melting point, high strength, high thermal conductivity, stability in aggressive media and low abrasion make titanium carbide indispensable in a many areas of human activity [1-6]. Titanium carbide is remarkable in that, according to the equilibrium state diagram, it has a wide homogeneity region in the titanium-carbon system [7]. The boundaries of this interval have not yet been fully studied, but it can be assumed that it is wider than $40-50$ at $\%$ of carbon at room 
temperature. $\mathrm{TiC}$ has a structure similar to that of $\mathrm{NaCl}(\mathrm{Bi})$ The carbon is usually located in the lattice between the points of the lattice, forming an interstitial solution. It was found that decreasing carbon content decreases the lattice period and hardness [2,3].

Most studies have been shown that TiC of stoichiometric composition is difficult to produce. A number of researchers note that it is impossible to obtain $\mathrm{TiC}$ in which all interstitial sites are occupied by carbon atoms [8-10]. One of the reasons is the ability of oxygen and nitrogen atoms to penetrate into the $\mathrm{TiC}$ lattice together with carbon atoms. The $\mathrm{TiO}$ and $\mathrm{TiN}$ phases also have a lattice similar to the $\mathrm{NaCl}(\mathrm{Bi})$ lattice and are isomorphous with $\mathrm{TiC}$. Therefore, oxygen and nitrogen pose great difficulties in obtaining pure TiC. Production of titanium carbide with the self-propagating high-temperature synthesis (SHS) method is characterized by the fact that the combustion reaction in the compact of titanium powder and carbon black completes in just a few seconds [11-18]. The synthesis is most often carried out in a protective inert atmosphere. In addition, raw titanium must contain the least possible amount of impurities, including oxygen. The combination of the structural characteristics of the hard inclusions (titanium carbide) and the metal binder (matrix) provides the functional properties of the composite material. There are many methods of producing metal matrix composites with titanium carbide [19-27]. Classical methods of powder metallurgy (sintering, hot pressing and extrusion) and combination of them with mechanical activation or chemical-thermal processes can be used. In addition, the structure formation of the metal matrix composite can occur both as a result of heat treatment of a powder's mixture containing a metal base with titanium carbide, and as a result of the synthesis of titanium with carbon components and other metals. In the first case, it is difficult to use a large amount of titanium carbide. In the second case, the excess carbon content is desirable in order to achieve an acceptable volume fraction of carbide. The method of producing a metal matrix composite by the SHS method is quite simple when the synthesis takes place directly during the reaction of titanium and carbon in the presence of a thermally-inert metal matrix [28-30]. In this case, a structure with carbides surrounded by a metal binder is formed directly during the synthesis process. This method allows us to achieve the optimum volume fraction, and a homogeneous distribution with a high degree of dispersion of titanium carbide that has a positive effect on the properties of the metal matrix composite. Such characteristics are difficult to achieve with the conventional method of introducing the titanium carbide into a metal matrix. As a rule, such a synthesized compact is quite fragile and easily subjected to grinding. After grinding, the resulting powder product is sieved into fractions. As a result, the finished powder can be obtained with a predetermined structure of a metal matrix composite based on titanium carbide. Subsequently, the synthesized powder can be used as consumables (feedstock) for surfacing processes and other additive production. The behavior of such powders under the conditions of the electron beam surfacing can be assessed by us already, where high-energy fast processes are realized. However, at the moment it is difficult to answer how the synthesized composite powders will behave under low-energy prolonged impact. This paper presents the results of our research, which were carried out in order to explain the behavior of such non-equilibrium heterogeneous structures during subsequent heat treatment.

\section{Materials and Methods}

\subsection{Materials and Experimental Procedure}

The powder materials under study were obtained in two stages:

(1). Synthesis of the powder base from the reaction mixture by a layerwise combustion mode in an argon atmosphere, followed by milling of the synthesized material and sieving of the necessary fraction.

(2). Vacuum sintering of the synthesized powders into compacts.

Standardized industrial powders were used in the experiment:

Titanium TPP-8 (POLEMA JSC, Tula, Russia) with dispersion 50-130 $\mu \mathrm{m}$;

Carbon black P-803 (Omsk Carbon Group, Omsk, Russia) $(<0.1 \mu \mathrm{m})$;

High-speed steel R6M5 (POLEMA JSC, Tula, Russia) (50-100 $\mu \mathrm{m})$; 
High-chromium cast iron PG-S27 (POLEMA JSC, Tula, Russia) (50-100 $\mu \mathrm{m})$;

Nickel-based self-fluxing alloy PR-N77H15S3R2 (POLEMA JSC, Tula, Russia) (50-100 $\mu \mathrm{m})$.

The titanium powder TPP- 8 contains no less than $99.4 \%$ of the primary component, and no more than $0.33 \%$ iron, $0.12 \%$ chlorine, and $0.1 \%$ oxygen. The high-speed steel powder contains $1 \%$ carbon, alloying dopants (Cr, $4 \%$; W, 6.5\%; Mo, 5\%; V, 2\%) and impurities ( $\mathrm{Si}, 0.5 \%$; $\mathrm{Mn}, 0.55 \%$; Ni, $0.4 \%$ ).

Powder mixing was carried out in stationary conditions using axial mixing machine SMU-PB-180 (Agromash, Moscow, Russia). The metal binder content is determined by the maximally possible volume fraction of the thermally-inert metal component that still permits the initiation and realization of the SHS process in a mixture of titanium, carbon black, and the chosen metal matrix powders. Calculation of the initial powder mixture was made based on the assumption that the estimated volume fraction of equiatomic titanium carbide is formed during SHS. The following compositions were chosen (Table 1).

Table 1. Compositions of experimental powder mixtures (SHS: Self-propagating high-temperature synthesis).

\begin{tabular}{cc}
\hline Composition Number & $\begin{array}{c}\text { The Calculated Content of Phases in the SHS Powders } \\
\text { (with the Assumption of Equiatomic TiC Formation) }\end{array}$ \\
\hline 1 & $\mathrm{TiC}+50 \mathrm{vol} \% \mathrm{Ti}$ \\
2 & $\mathrm{TiC}+60 \mathrm{vol} \% \mathrm{Ti}$ \\
3 & $\mathrm{TiC}+50 \mathrm{vol} \% \mathrm{high}-\mathrm{chromium}$ cast iron \\
4 & $\mathrm{TiC}+50 \mathrm{vol} \%$ high-speed steel \\
5 & $\mathrm{TiC}+20 \mathrm{vol} \%$ nickel-based self-fluxing alloy \\
6 & $\mathrm{TiC}+30 \mathrm{vol} \%$ nickel-based self-fluxing alloy \\
7 & $\mathrm{TiC}+40 \mathrm{vol} \%$ nickel-based self-fluxing alloy \\
8 & $\mathrm{TiC}+50 \mathrm{vol} \%$ nickel-based self-fluxing alloy \\
\hline
\end{tabular}

The powder compositions were pressed into cylindrical compacts $35 \mathrm{~mm}$ in diameter to facilitate the passage of the combustion front. Then the compacts were placed in a reactor for synthesis in a layerwise combustion mode using argon gas with an excess pressure of about $0.5 \mathrm{~atm}$. The reaction of layerwise combustion was initiated using short-term heating by means of a molybdenum filament of an igniting tablet pressed from the powder mixture of titanium and silicon corresponding to the stoichiometric composition $\mathrm{Ti}_{5} \mathrm{Si}_{3}$. The combustion product remains of titanium silicide were removed after synthesis; the reacted compact was milled and sieved into fractions. Using this procedure, synthesized powders of all investigated compositions containing titanium carbide were obtained [28-32]. The typical microstructure and morphology of the studied synthesized powder compositions are shown in Figure 1. The finest fraction (not exceeding $50 \mu \mathrm{m}$ ) was selected for studying the behavior of composite powders under vacuum sintering. Cylindrical specimens pressed using a plasticizer with residual porosity not exceeding $45 \%$ were placed in a vacuum furnace and heated in vacuum at $10^{-2} \mathrm{~Pa}$ with a heating rate of $3-5{ }^{\circ} \mathrm{C} \cdot \mathrm{min}^{-1}$ to achieve sintering temperatures of $1300{ }^{\circ} \mathrm{C}$ and $1350{ }^{\circ} \mathrm{C}$. The holding time at the sintering temperature was $3 \mathrm{~h}$.

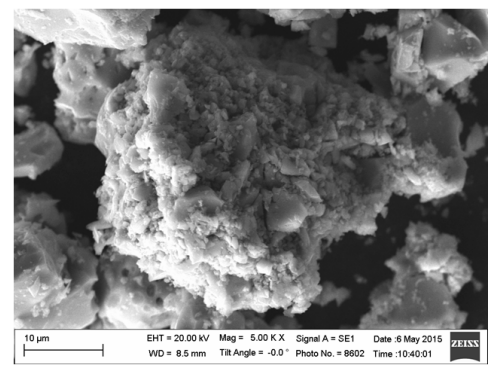

(a)

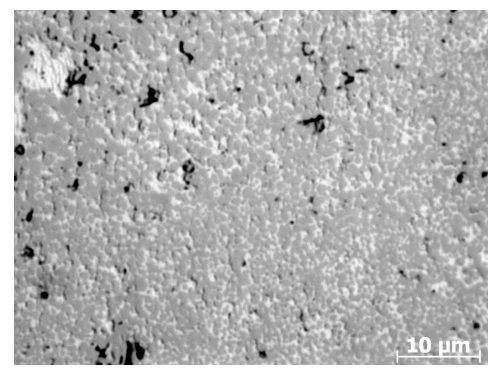

(b)

Figure 1. Cont. 


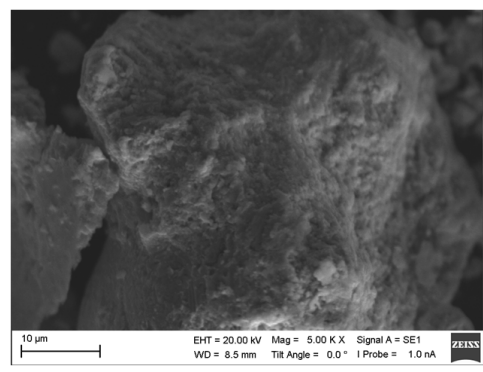

(c)

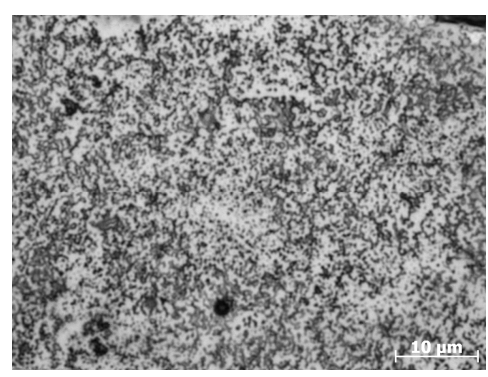

(d)

Figure 1. Morphology and microstructure of the following powder composites: (a,b) TiC-50\% binder of high-chromium cast iron; and (c,d) TiC-50\% binder of high-speed steel.

\subsection{Characterisation}

The density of specimens was measured before and after sintering by the Archimedes method according to the ASTM B962-17 standard. Metallographic specimens were prepared using the standard metallographic procedures: grinding with abrasive materials; fine polishing and etching in Keller's reagent ( $95 \mathrm{~mL} \mathrm{H}_{2} \mathrm{O} ; 2.5 \mathrm{~mL} \mathrm{HNO}_{3} ; 1.5 \mathrm{~mL} \mathrm{HCl} ; 1 \mathrm{~mL} \mathrm{HF}$ ) for 5-10 s. An AXIOVERT-200MAT metallographic microscope (Carl Zeiss, Oberkochen, Germany) and a LEO EVO 50 scanning electron microscope (Carl Zeiss, Oberkochen, Germany) were used for the analysis of the SHS-powder morphology, the microstructure of the SHS-powder, and the sintered compacts. The phase composition was determined by $\mathrm{X}$-ray analysis using $\mathrm{Co}_{\alpha}$. For phase identification and calculation of the lattice parameters of the phases was used the X-ray data of the ASTM data file and the software package PDWin (4.0, NPP Bourevestnik, Saint-Petersburg, Russia, 2015).

\section{Results}

The results of vacuum sintering of $\mathrm{SH}$-synthesized metal-matrix powders based on titanium carbide are presented in Figure 2. These results are best analyzed by the change in density before and after sintering. The density of the green compacts varies from $3.1 \mathrm{~g} / \mathrm{cm}^{2}$ to $3.7 \mathrm{~g} / \mathrm{cm}^{2}$, depending on the metal binder used. Our estimates show that this density corresponds to approximately $60-70 \%$ of the theoretical maximum for the respective system. In our studies, we preferred to use the actual density values of the sintered compacts. The porosity was determined by the metallographic method (quantitative metallography). In multicomponent powder materials, it is difficult to calculate the theoretical density of sintered compacts to estimate their residual porosity, since the real phase relationship after sintering is unknown.

The experimental results show that vacuum sintering at $1300-1350{ }^{\circ} \mathrm{C}$ has a significant effect on the structure formation of composite materials sintered from $\mathrm{SH}$-synthesized powders, i.e., from the already-reacted powder composition. The process of diffusion interaction was once again activated during the subsequent sintering. Comparing the values of densification for different compositions in Figure 2, it is evident that the qualitative composition of the metal matrix affects the sinterability of the composite powder compacts.

Titanium, as a metallic binder, will be well-sintered in any temperature range (Figure 3). Its inclusions, which stimulate densification of the compact during sintering, are insignificant (by volume) relative to the dominant titanium carbide (Figure 2a). However, the interaction of free surfaces of "titanium-titanium" is not the only factor leading to shrinkage of the samples. According to microstructure analysis, an additional carbon migration occurs during sintering, which increases the proportion of non-stoichiometric titanium carbide (Figure 3b). 


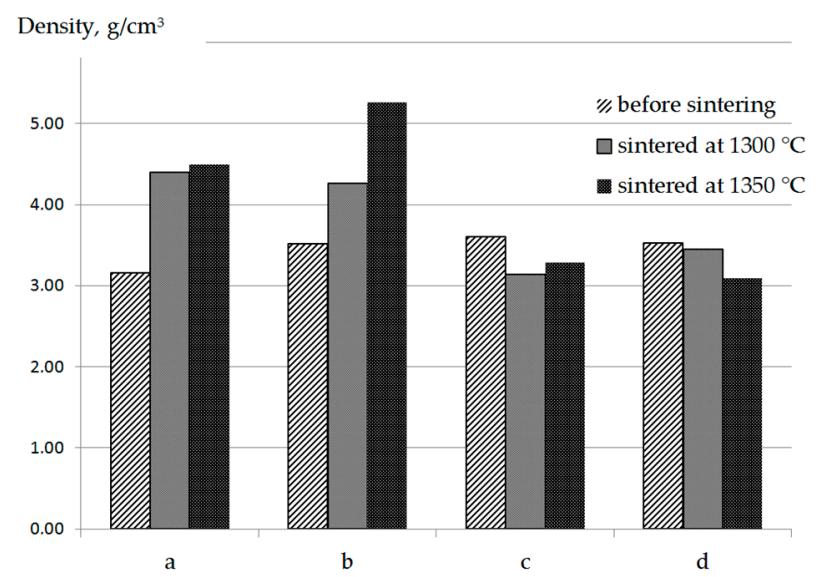

Figure 2. Density change of TiC-Me (titanium carbide with metal binder) compacts sintered at different temperature: (a) TiC-50\% Ti; (b) TiC-50\% high-chromium cast iron; (c) TiC-50\% nickel-based self-fluxing alloy; (d) TiC-50\% high-speed steel.

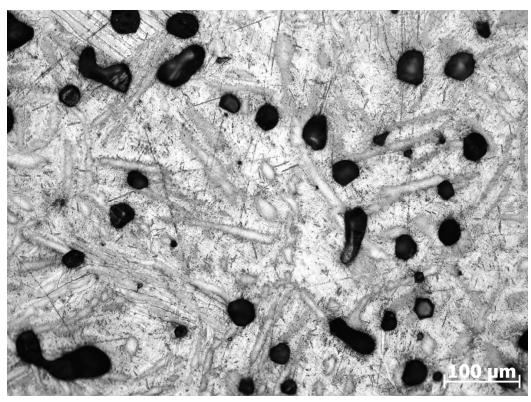

(a)

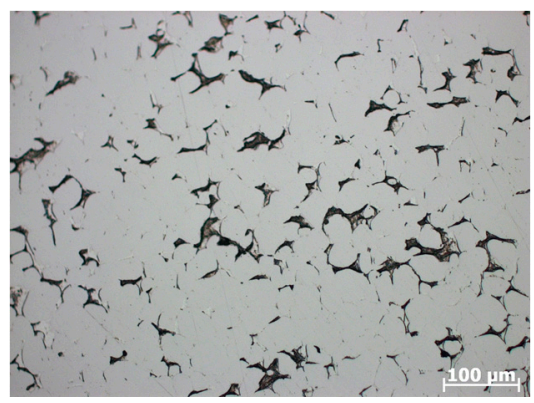

(b)

Figure 3. Microstructure of titanium powder: (a) TiC-50\% Ti synthesized powder before sintering at $1350{ }^{\circ} \mathrm{C}$; (b) after sintering at $1350{ }^{\circ} \mathrm{C}$.

Composite powders with a high-chromium cast iron binder also densify well (Figure 4). In this case, it can be assumed that the fixed carbon, which is a component of the cast iron alloy, acts as an activator of sintering. Evidently, its affinity to titanium is stronger than the bond with iron and other alloying components (chrome) that are alloy additives of cast iron.

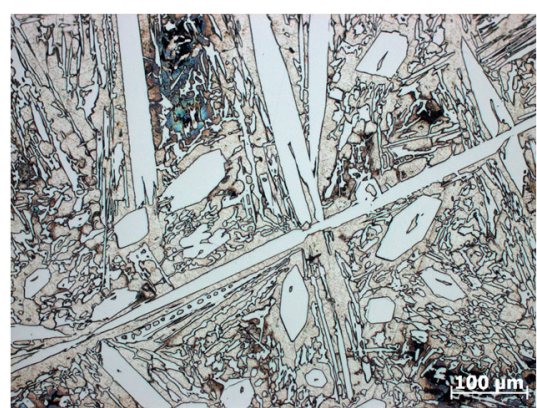

(a)

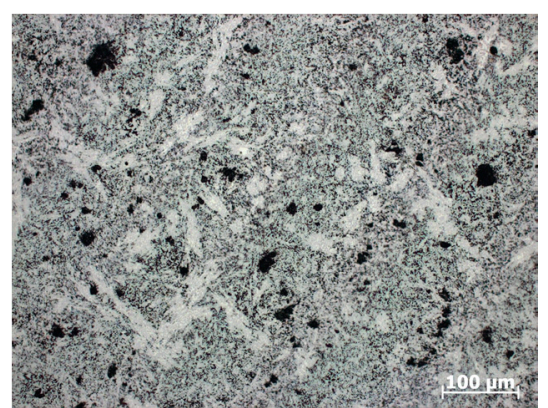

(b)

Figure 4. Microstructure of high-chromium cast iron powder: (a) TiC-50\% high-chromium cast iron binder synthesized powder before sintering at $1300{ }^{\circ} \mathrm{C}$; (b) after sintering at $1300{ }^{\circ} \mathrm{C}$. 
The use of other alloys (high-speed steel and nickel-based self-fluxing alloy) as a metallic binder demonstrates the opposite effect (Figure 5). Vacuum sintering of these synthesized powders causes the residual porosity increase that leads to a density decrease.

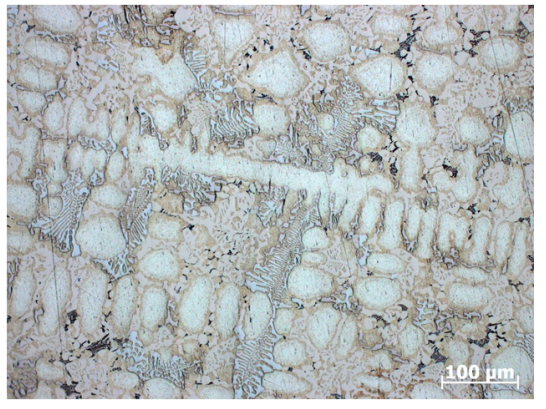

(a)

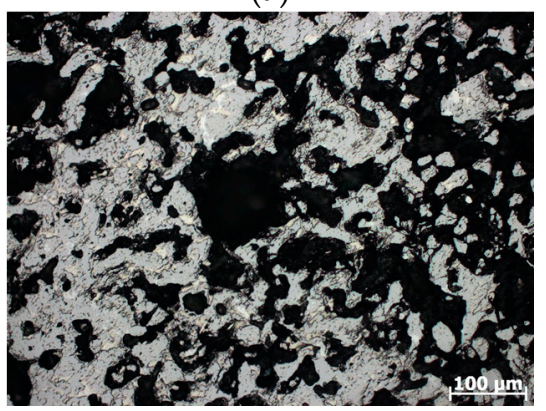

(c)

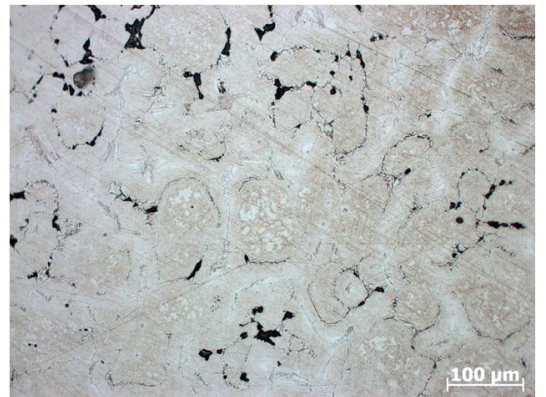

(b)

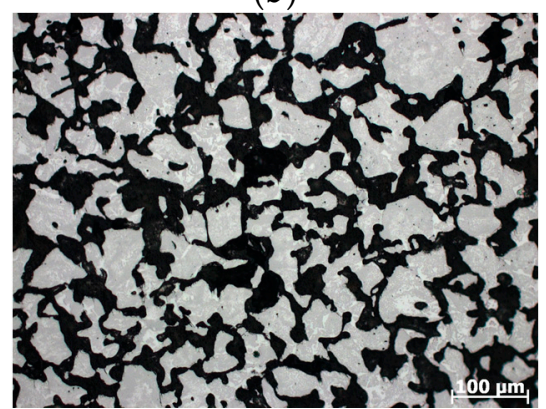

(d)

Figure 5. Sintered at $1300{ }^{\circ} \mathrm{C}$ : (a) microstructure of nickel-based self-fluxing alloy powder; (b) high-speed steel powder; (c) TiC-50\% nickel-based self-fluxing alloy synthesized powder; and (d) TiC-50\% high-speed steel synthesized powder.

Although the powders of high-speed steel and nickel-based self-fluxing alloys themselves are well-sintered (Figure 5a,b), in the presence of the titanium carbide the "negative" redistribution of the carbon takes place towards the metallic binder. This is assisted by the presence of carbon-active components in the alloys of high-speed steel and nickel-based self-fluxing alloy: Tungsten and molybdenum in high-speed steel and chromium in the nickel-based self-fluxing alloy, where nickel can also have an active influence on the titanium bound in the carbide.

It was found that the non-equilibrium metal-matrix structure of the powders formed as a result of SHS by the layerwise combustion method consisting mainly of non-stoichiometric titanium carbide [30,31]. Many works are devoted to the non-stoichiometricity of titanium carbide [6,8-10]. Unfortunately, there are not enough publications showing the influence of this factor on the various processes of structure formation. Our research shows that subsequent heat treatment in the mode of vacuum sintering activates the tendency of the system to approach a more equilibrated state through the redistribution of fixed carbon. In fact, despite the high affinity of carbon to titanium, some carbon atoms leave the lattice of titanium carbide, which already has a carbon deficit. Some coarsening and coalescence of the carbide particles after vacuum sintering occurs in comparison with the distribution and dispersion of carbide inclusions in the synthesized powders before heat treatment (Figure 6).

Figure 7 shows the effect of temperature on the sinterability of TiC-50\% Ti SHS-powders. The metal binder type of synthesized powders have different effects on the sinterability of compacts. In the case of a maximum binder content of titanium, high-chromium cast iron, and a nickel alloy. An increase in temperature from $1300{ }^{\circ} \mathrm{C}$ to $1350{ }^{\circ} \mathrm{C}$ stimulates densification; in the case of a high-speed steel binder, however, the density at $1350{ }^{\circ} \mathrm{C}$ was less than at $1300{ }^{\circ} \mathrm{C}$. It is supposed by us that the temperature of $1350{ }^{\circ} \mathrm{C}$ is insufficient to cause the shrinkage process to become dominant. At this temperature, the alloy formation local processes continue, causing the formation of rigid skeletons. 


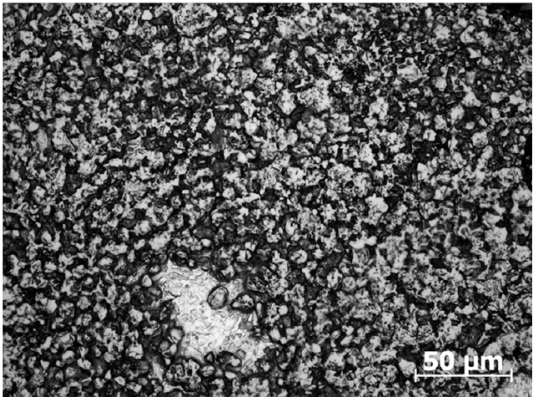

(a)

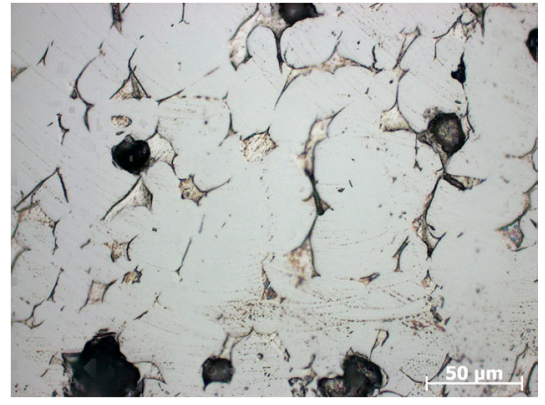

(b)

Figure 6. Microstructure of TiC-50\% Ti synthesized powder: (a) Before sintering at $1350{ }^{\circ} \mathrm{C}$ and (b) after sintering at $1350^{\circ} \mathrm{C}$.

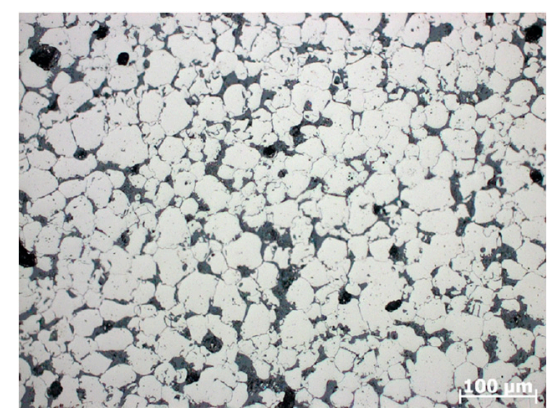

(a)

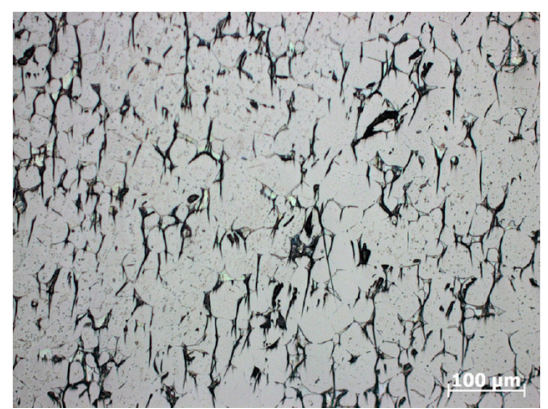

(b)

Figure 7. Microstructure of TiC-50\% Ti synthesized powder sintered at: (a) $1300{ }^{\circ} \mathrm{C}$ and (b) $1350{ }^{\circ} \mathrm{C}$.

In the latter compositions, a rigid skeleton is formed from the high-alloy metal binder already at $1300^{\circ} \mathrm{C}$. This rigid skeleton prevents consolidation of the material with an increasing temperature up to the melting point of the binder.

At the same time, there is no noticeable qualitative change in the phase composition of the synthesized powder materials after sintering (Figure 8). The main phases were recognized, and were identical both for synthesized powder and for sintered compacts from them. The formation of any additional phases was not detected. However, a number of the X-ray diffraction (XRD) lines have a superposed view that may indicate the possibility of the existence of additional phases in small volume fractions. It is assumed that additional structural studies are needed in this case.

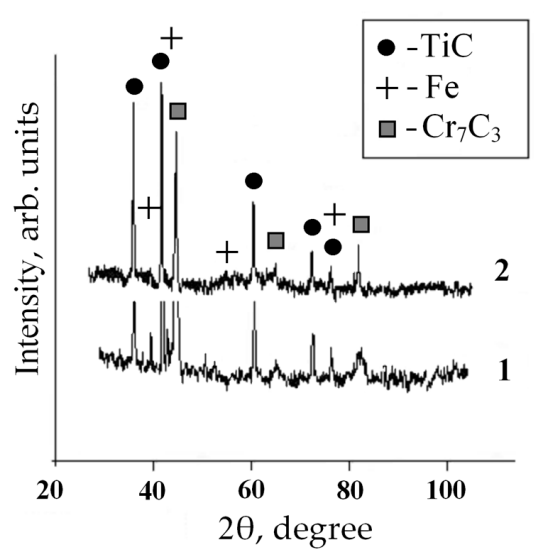

(a)

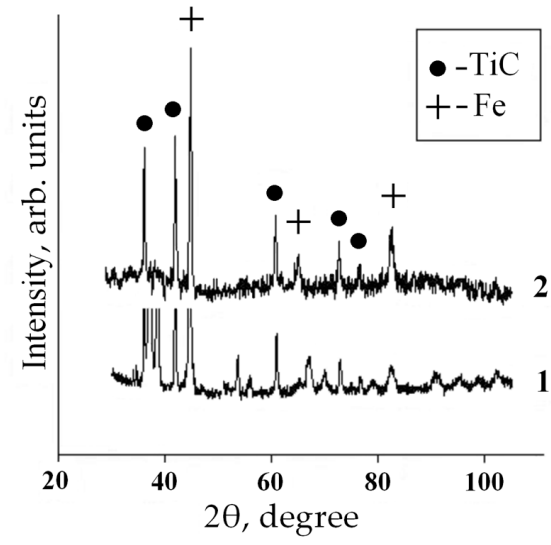

(b)

Figure 8. Cont. 


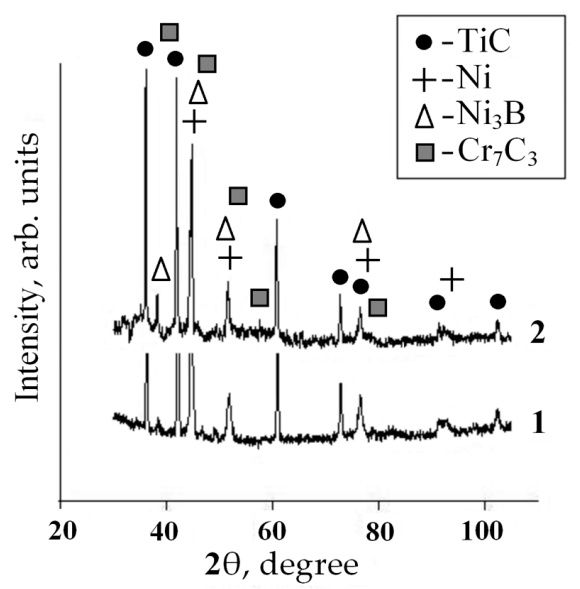

(c)

Figure 8. XRD patterns of the SHS-powder materials before (1) and after (2) sintering at $1350{ }^{\circ} \mathrm{C}$ : (a) TiC-50\% high-chromium cast iron binder; (b) TiC-50\% high-speed steel binder; (c) TiC-50\% binder of nickel-based self-fluxing alloy. (SHS: Self-propagating high-temperature synthesis).

The volume fraction of the metal binder affects the density change of the sintered materials depending on its type. In the case of titanium binder, an increase in its bulk content contributes to the shrinkage of the sintered compacts. In the case of a nickel alloy matrix, on the contrary, an increase in the volume fraction of the binder leads to an increased volume growth of the compacts sintered at $1300{ }^{\circ} \mathrm{C}$ (Table 2). When the temperature reaches $1350^{\circ} \mathrm{C}$, the densification processes starts to dominate for the compositions with $40-50 \%$ nickel-based binder.

Table 2. Relative densification of the SHS compacts with various volume content of metal binder sintered at $1350{ }^{\circ} \mathrm{C}$.

\begin{tabular}{ccc}
\hline Composition & \multicolumn{2}{c}{ Relative Densification, $\%$} \\
\cline { 2 - 3 } & $\boldsymbol{T}_{\text {sin }}=\mathbf{1 3 0 0}{ }^{\circ} \mathbf{C}$ & $\boldsymbol{T}_{\text {sin }}=\mathbf{1 3 5 0}{ }^{\circ} \mathbf{C}$ \\
\hline $\mathrm{TiC}+50$ vol \% Ti & 40.1 & 42.0 \\
$\mathrm{TiC}+60$ vol \% Ti & 43.2 & 50.6 \\
$\mathrm{TiC}+20$ vol \% nickel-based self-fluxing alloy & -10.2 & -14.1 \\
$\mathrm{TiC}+30$ vol \% nickel-based self-fluxing alloy & -11.3 & -12.5 \\
$\mathrm{TiC}+40$ vol \% nickel-based self-fluxing alloy & -12.9 & -9.2 \\
$\mathrm{TiC}+50$ vol \% nickel-based self-fluxing alloy & -13.5 & -8.1 \\
\hline
\end{tabular}

\section{Discussion}

The results of our research show that metal matrix composites "TiC-metal binder" synthesized from powders in a layerwise combustion mode have a non-stoichiometric composition and are in a non-equilibrium state. It is assumed by us that carbon rearrangement occurs not only in the carbide phase, but also at the interface between $\mathrm{TiC}$ and the metal matrix upon subsequent heat treatment. Powder-synthesized composite materials of the type "TiC-high-chromium cast iron" and "TiC-Ti" exhibit significant densification during vacuum sintering at temperatures starting from $1250^{\circ} \mathrm{C}$, up to $1300{ }^{\circ} \mathrm{C}$. Conversely, use of high-speed steel and nickel-based self-fluxing alloy as the metal binder leads to an increased pore fraction by volume and, as a result, to an increased volume growth of specimens during sintering. The rise of the temperature up to $1350{ }^{\circ} \mathrm{C}$ only increases this expansion. For these multicomponent composites it is necessary to change a composition of synthesized powder by means of metal binder addition. The ability of the two studied compositions ("TiC-high-chromium cast iron" and "TiC-Ti") to significantly densify during sintering at temperatures lower than the melting 
point of the metal matrix may be of interest for the design of equipment for additive manufacturing, including 3D-printing of composite materials at reduced temperatures.

Acknowledgments: The research was funded from Russian Science Foundation, grant number 17-19-01425. The experimental calculations were carried out at Tomsk Polytechnic University within the framework of Tomsk Polytechnic University Competitiveness Enhancement Program grant.

Author Contributions: Elena N. Korosteleva conceived and designed the experiments, analyzed the data, and planned the manuscript; Victoria V. Korzhova conducted the experimental work for XRD analysis and discussed the results; Maksim G. Krinitcyn carried out the experiments for sintering and microstructure analysis.

Conflicts of Interest: The authors declare no conflict of interest.

\section{References}

1. Cui, C.; Hu, B.; Zhao, L.; Liu, S. Titanium alloy production technology, market prospects and industry development. Mater. Des. 2011, 32, 1684-1691. [CrossRef]

2. Pierson, H.O. Handbook of Refractory Carbides and Nitrides: Properties, Characteristics, Processing and Applications, 1st ed.; Noyes publications: Westwood, NJ, USA, 1996.

3. Weimer, A.W. Carbide, Nitride and Boride Materials Synthesis and Processing; Springer Science \& Business Media: Dordrecht, The Netherlands, 2012.

4. Herderick, E. Additive manufacturing of metals: A review. Mater. Sci. Technol. 2011, 1413-1425.

5. Gong, X.; Anderson, T.; Chou, K. Review on powder-based electron beam additive manufacturing technology. Manuf. Rev. 2014, 1. [CrossRef]

6. Shabalin, I.L.; Luchka, M.V.; Shabalin, L.I. Vacuum SHS in systems with group IV transition metals for production of ceramic compositions. Phys. Chem. Solid State 2007, 8, 159-175.

7. Okamoto, H. Phase Diagrams for Binary Alloys, 2nd ed.; ASM International: Materials Park, OH, USA, 2010; pp. 176-189.

8. Wanjara, P.; Drew, R.A.L.; Root, J.; Yue, S. Evidence for stable stoichiometric $\mathrm{Ti}_{2} \mathrm{C}$ at the interface in $\mathrm{TiC}$ particulate reinforced Ti alloy composites. Acta Mater. 2000, 48, 1443-1450. [CrossRef]

9. Quinn, C.J.; Kohlstedt, D.L. Solid-state reaction between titanium carbide and titanium metal. J. Am. Ceram. Soc. 1984, 67, 305-310. [CrossRef]

10. Yang, Y.F.; Wang, H.Y.; Zhang, J.; Zhao, R.Y.; Liang, Y.H.; Jiang, Q.C. Lattice parameter and stoichiometry of $\mathrm{TiC}_{\mathrm{x}}$ produced in the Ti-C and Ni-Ti-C systems by self-propagating high-temperature synthesis. J. Am. Ceram. Soc. 2008, 91, 2736-2739. [CrossRef]

11. Merzhanov, A.G. History and recent developments in SHS. Ceram. Int. 1995, 21, 371-379. [CrossRef]

12. Merzhanov, A.G. Combustion processes that synthesize materials. J. Mater. Process. Technol. 1996, 56, $222-241$. [CrossRef]

13. Munir, Z.A.; Anselmi-Tamburini, U. Self-propagating exothermic reactions: the synthesis of high-temperature materials by combustion. Mater. Sci. Rep. 1989, 3, 277-365. [CrossRef]

14. LaSalvia, J.C.; Meyer, L.W.; Meyers, M.A. Densification of reaction-synthesized titanium carbide by high-velocity forging. J. Am. Ceram. Soc. 1992, 75, 592-602. [CrossRef]

15. Strutt, E.R.; Olevsky, E.A.; Meyers, M.A. Combustion synthesis/quasi-isostatic pressing of TiC-NiTi cermets: Processing and mechanical response. J. Mater. Sci. 2008, 43, 6513-6526. [CrossRef]

16. Samokhin, A.V.; Alekseev, N.V.; Sinayskiy, M.A.; Tsvetkov, J.V. Thermodynamic model of high-temperature synthesis of oxygen-free titanium compounds from titanium tetrachloride. Contemp. Eng. Sci. 2015, 8, 1449-1460. [CrossRef]

17. Nersisyan, H.H.; Lee, J.H.; Won, C.W. Self-propagating high-temperature synthesis of nano-sized titanium carbide powder. J. Mater. Res. 2002, 17, 2859-2864. [CrossRef]

18. Kobashi, M.; Ichioka, D.; Kanetake, N. Combustion synthesis of porous TiC/Ti composite by a self-propagating mode. Materials 2010, 3, 3939-3947. [CrossRef]

19. Gülsoy, H.O.; Gunay, V.; Baykara, T. Influence of TiC, TiN and TiC(N) additions on sintering and mechanical properties of injection moulded titanium based metal matrix composites. Powder Metall. 2015, 58, 30-35. [CrossRef]

20. Kim, Y.J.; Chung, H.; Kang, S.J. In situ formation of titanium carbide in titanium powder compacts by gas-solid reaction. Compos. Part A Appl. Sci. Manuf. 2001, 32, 731-738. [CrossRef] 
21. Roger, J.; Gardiola, B.; Andrieux, J.; Viala, J.C.; Dezellus, O. Synthesis of Ti matrix composites reinforced with TiC particles: thermodynamic equilibrium and change in microstructure. J. Mater. Sci. 2017, 52, 4129-4141. [CrossRef]

22. El-Eskandarany, M.S. Structure and properties of nanocrystalline TiC full-density bulk alloy consolidated from mechanically reacted powders. J. Alloys Compd. 2000, 305, 225-238. [CrossRef]

23. Winkler, B.; Juarez-Arellano, E.A.; Friedrich, A.; Bayarjargal, L.; Yan, J.; Clark, S.M. Reaction of titanium with carbon in a laser heated diamond anvil cell and reevaluation of a proposed pressure-induced structural phase transition of TiC. J. Alloys Compd. 2009, 478, 392-397. [CrossRef]

24. Yan, Y.; Zheng, Y.; Yu, H.; Bu, H.; Cheng, X.; Zhao, N. Effect of sintering temperature on the microstructure and mechanical properties of $\mathrm{Ti}(\mathrm{C}, \mathrm{N})$-based cermets. Powder Metall. Met. Ceram. 2007, 46, 449-453. [CrossRef]

25. Viljus, M.; Pirso, J.; Juhani, K.; Letunovitš, S. Structure Formation in Ti-C-Ni-Mo Composites during Reactive Sintering. Mater. Sci. 2012, 18, 62-65. [CrossRef]

26. Luo, S.D.; Li, Q.; Tian, J.; Wang, C.; Yan, M.; Schaffer, G.B.; Qian, M. Self-assembled, aligned TiC nanoplatelet-reinforced titanium composites with outstanding compressive properties. Scr. Mater. 2013, 69, 29-32. [CrossRef]

27. Li, S.; Sun, B.; Imai, H.; Kondoh, K. Powder metallurgy Ti-TiC metal matrix composites prepared by in situ reactive processing of Ti-VGCFs system. Carbon 2013, 61, 216-228. [CrossRef]

28. Kalambaeva, S.S.; Korosteleva, E.N.; Pribytkov, G.A. Structure of Composite Powders “TiC-high Chromium Cast Iron Binder" Produced by SHS Method. In Proceedings of the International Conference on Mechanical Engineering, Automation and Control Systems, Tomsk, Russia, 16-18 October 2014. [CrossRef]

29. Krinitcyn, M.G.; Pribytkov, G.A.; Durakov, V.G. Structure and properties of electron beam coatings, overlaid of SHS composite powders “TiC-Ti”, synthesized in air. Key Eng. Mater. 2016, 685, 719-723. [CrossRef]

30. Korosteleva, E.N.; Pribytkov, G.A.; Krinitcyn, M.G.; Baranovskii, A.V.; Korzhova, V.V.; Strelnitskij, V.E. Fabrication of "TiC-HSS steel binder" composite powders by self-propagating high temperature synthesis. Key Eng. Mater. 2016, 712, 195-199. [CrossRef]

31. Korosteleva, E.N.; Pribytkov, G.A.; Krinitcyn, M.G.; Baranovskii, A.V.; Korzhova, V.V. Problems of Development and Application of Metal Matrix Composite Powders for Additive Technologies. IOP Conf. Ser. Mater. Sci. Eng. 2016, 140. [CrossRef]

32. Dudina, D.V.; Pribytkov, G.A.; Krinitcyn, M.G.; Korchagin, M.A.; Bulina, N.V.; Bokhonov, B.B.; Batraev, I.S.; Rybin, D.K.; Ulianitsky, V.Y. Detonation spraying behavior of $\mathrm{TiC}_{\mathrm{x}}-\mathrm{Ti}$ powders and the role of reactive processes in the coating formation. Ceram. Int. 2016, 42, 690-696. [CrossRef] 